\title{
PROMOÇÃO EM SAÚDE MENTAL: a enfermagem criando e intervindo com histórias infantis ${ }^{a}$
}

Gimene Cardozo BRAGA ${ }^{b}$, Esal ba M aria SI LVEIRAc,

Valéria Cristina Christello COIM BRA ${ }^{d}$, Adrize Rutz PORT Oe

\section{RESUMO}

Este trabal ho refere-se à importância das histórias infantis enquanto instrumento, para a ação de enfer magem e a promoção da saúde mental na infância. 0 bjetivou-se verificar o (re)conhecimento das emoções de crianças, através de histórias específicas para a saúde. T rata-se de um estudo descritivo-exploratório de natureza qualitativa, realizado em sete encontros de grupo com seis crianças de sete a dez anos, em um ambulatório de saúde mental infantil. $\mathrm{N}$ a coleta de dados utilizaram-se como instrumentos: seis histórias infantis, o jogo das emoções, as carinhas emotivas, desenhos, pinturas e esculturas em argila. U tilizou-se a anál ise temática, na qual emergiu o tema: o (re)conhecimento das emoções. As crianças reconheceram quatro emoções básicas: tristeza, al egria, medo e raiva. Constatou-se no estudo que a criação de histórias contextualizadas e a estratégia do grupo de contação podem ser úteis como ferramenta para a pesquisa e qualificação das ações de enfer magem na promoção de saúde mental infantil.

D escritores: Saúde mental. Jogos e brinquedos. Enfer magem psiquiátrica.

\section{RESUMEN}

E ste artículo se refiere a la importancia de los cuentos infantiles como una herramienta para la acción de enfermería y la promoción de la salud mental en la infancia. Se buscó verificar el reconocimiento de las emociones, a través de historias específicas para la salud. E s un estudio cual itativ y y descriptivo- exploratorio, fuer on realizados si ete encuentros con seis niños, entre siete y diez años, de un servicio de sal ud mental infantil. E n la recogida de datos se utilizaron: seis historias infantiles, el juego de emociones, caras emotivas, dibujos, pinturas y esculturas en arcilla. Seutilizó el análisis temático, en el que surgió: el reconocimiento de las emociones. $L$ os niños reconocen cuatro emociones: tristeza, alegría, miedo y rabia. L a creación de historias contextualizadasy la estrategia del grupo denar ración decuentos, puedeser útil como her ramienta para la investigación y cualificación de las acciones de enfermería en la promoción de la salud mental.

D escriptores: Salud mental. J uego e implementos de juego. E nfermería psiquiátrica.

Título: P romoción de la salud mental: la enfermería creando einterviniendo con cuentos infantiles.

\section{ABST RACT}

This paper refers to the importance of the childish stories as an instrument, for the nursing action and the mental health promotion in childhood. The objective was to verify the recognition of the children's emotions, through stories specific to health. This is a descriptive exploratory study of a qual itative nature, conducted in seven groups meetings with six children aged seven to ten years in an outpatient childish mental health. In the data collection the foll owing were used as instruments: six fair y tales, the play of emotions, emotional faces, drawings, paintings and clay sculptures. Thematic analysis was used, in which the following emerged: the recognition of emotions. The children recognized four basics emotions: sadness, joy, fear and anger. It was found in the study that the creation of contextualized stories and the strategy of storytelling group may be useful as a tool for research and qualification of nursing actions, to promote children's mental health.

D escriptors: M ental health. P lay and playthings. P sychiatric nursing.

Title: P romotion in mental health: nursing creating and intervening with children's stories.

\footnotetext{
a Parte do estudo monográfico apresentado em 2009 ao Programa de Residência Multiprofissional em Saúde (PREM US) da Pontifícia Universidade Católica do Rio Grande do Sul (PUCRS).

- Enfermeira E specialista em Saúde M ental, M estranda do Programa de Pós-G raduação em Enfermagem da U niversidade Federal de Pelotas (U F Pel), Bolsista de D emanda Social da Coordenação de A perfeiçoamento de Pessoal de Nível Superior (CAPES), Pelotas, Rio Grande do Sul, Brasil.

' D outora em Serviço Social, Professora da Faculdade de Serviço Social e Preceptora da Equipe de Saúde M ental do PRE M U S/ PU CRS, Porto Alegre, Rio Grande do sul, Brasil.

d D outora em Enfermagem Psiquiátrica, Professora A djunta da Faculdade de Enfer magem e do Programa de Pós-G raduação M estrado em Enfer magem da U F Pel, Pelotas, Rio Grande do Sul, Brasil.

e Enfermeira, M estranda do Programa de Pós-Graduação em Enfermagem da U F Pel, Bolsista de Demanda Social CAPES, Pelotas, Rio Grande do Sul, Brasil.
} 


\section{INT RODUÇÃO}

A criança, desde o início da vida, utiliza-se do brinquedo como principal forma de estruturação e enfrentamento das emoções complexas, estabelecendo um espaço transicional, que a auxilia na superação das angústias, no controle das ideias e dos impulsos e na constituição singularizada. Para tanto, as histórias constituem-se em um instrumento lúdico capaz de apreender os conteúdos emocionais infantis ${ }^{(1)}$ e, quando elaboradas para as práticas em saúde, tornam-se uma ferramenta viável ao cuidado infantil(2).

N essa perspectiva, as histórias tornam-se excelentes mediadores terapêuticos infantis, por terem uma estrutura formada em torno das noções de tempo, de espaço, de personagens, de intrigas e de mudanças, as quais possibilitam às crianças internalizar vários desses aspectos do mundo externo ${ }^{(3-5)}$.

A lém disso, as histórias favorecem a (re)significação emocional infantil por meio da historicização, trabalhando o presente para conviver com 0 passado, de tal modo que possibilitam a construção do simbólico, a partir dos significantes que foram adotados de seus pais, do social. Dessa forma, oferecem-se subsídios para que a criança possa inventar sua própria história pelo brincar ${ }^{(6)}$.

Portanto, o relato de histórias é um instrumento viável na investigação de emoções e na relação interpessoal do enfermeiro, como uma ação que aproxima o profissional dos processos psíquicos infantis ${ }^{(7)}$. A demais, a narrativa, se explorada em grupos de crianças, favorece 0 entendimento dos sentimentos e auxilia nas intervenções terapêuticas por meio da reconstrução desses processos internos de maneira conjunta e horizontal ${ }^{(4)}$. Quando, além das histórias, são incluídos outros mediadores, como o desenho e o jogo, tem-se uma excel ente estratégia de promoção em saúde mental (5).

Promoção em saúde é um processo de mobilização de sujeitos e comunidades que articulam saberes técnicos e populares na resolução de problemas, considerando a qualidade de vida, a equidade, a democracia, a cidadania e a co-responsabilização destes nessa ação, a qual busca responder às necessidades sociais ${ }^{(8,9)}$. Como o grupo é um espaço hábil na promoção da sociabilidade da criança, sendo capaz de compreender 0 acolhimento e a descoberta de si e do outro(2), amplia-se às ações em saúde mental o conceito de promoção em saúde.
D estarte, promoção de saúde mental é entendida por fortalecer e potencializar os processos saudáveis de reconhecimento e empoderamento das emoções, pensamentos e reações comportamentais.

Diante da relevância de pesquisas sobre intervenções assistenciais com histórias infantis, observou-se que a maioria dos trabal hos de enfermagem utiliza-se de fábulas e contos tradicionais como forma de humanizar o cuidado $0^{(7,10,11)}$. Entretanto, verificou-se que histórias infantis, elaboradas com base em possíveis vivências cotidianas das crianças, assumem o papel de educar em saúde, assim como de promover a saúde mental, por meio da identificação direta das crianças com a problematização apresentada nas histórias ${ }^{(2)}$.

A ssim, este estudo objetivou verificar o reconhecimento das emoções de crianças com o uso de histórias específicas à saúde.

\section{MÉTODOS}

Este estudo caracteriza-se como descritivoexploratório de natureza qualitativa, sendo realizado em um ambulatório público de saúde mental infantil, da capital gaúcha, com seis crianças de 7 a 10 anos de idade. As crianças foram encaminhadas ao serviço por motivo de irritabilidade, agressividade, medo, choro em excesso, dificuldades de relacionamento, indicativos de sintomatologia leve e necessidade de acolhimento especializado em saúde mental.

A coleta de dados ocorreu nos meses de junho a julho de 2009, pela técnica de grupo operativo, em sete encontros semanais gravados e com duração de uma hora. T ambém, foram registradas as principais impressões em diário de campo por um observador participante. 0 grupo operativo é centrado na tarefa e propõe uma aprendizagem, de forma a retrabalhar e reaprender por meio da tar efa os problemas pessoais ${ }^{(12)}$. D urante o grupo, realizou-se a contação de seis histórias infantis específicas à saúde com o tema emoções, produzidas pela autora do estudo, além de outros instrumentos como: seis carinhas emotivas, desenhos, argilas, pinturas e jogo das emoções.

As histórias foram revisadas por uma equipe técnica (psicopedagoga, psicóloga e enfermeira) e apresentam a personagem principal, A ninha, vivenciando situações emocionais de ansiedade, felicidade, tristeza, tranquilidade, chateação e irritabilidade. A ordem de contação das histórias foi es- 
colhida pelo grupo. Cada história foi narrada até a metade, para possibilitar às crianças momentos de expressão das emoções e a introdução de questões norteadoras de acordo com a categoria operacional: 0 que é? 0 que você faz quando? E o quel quem te deixa? A pós serem concluídas, tinham-se como tarefa desenhos, esculturas e pinturas.

E mpregou-se o desenho da história, para remeter à reconstrução da narrativa, verificando as re- lações estabelecidas entre a história e as identificações da criança e o desenho espontâneo, que proporciona o conhecimento do universo simbólico como um espaço de experimentação, criatividade e manifestação emocional|(13).

A sel eção dos instrumentos foi realizada, previamente, pela pesquisadora, e esses foram introduzidos de acordo com as necessidades do grupo. 0 Q uadro 1 mostra a disposição dos encontros ${ }^{(14)}$.

\begin{tabular}{|c|c|c|c|c|c|c|c|}
\hline & Encontro 1 & Encontro 2 & Encontro 3 & Encontro 4 & Encontro 5 & Encontro 6 & Encontro 7 \\
\hline $\begin{array}{c}\text { História } \\
\text { Trabalhada }\end{array}$ & $\begin{array}{c}\text { O Dia } \\
\text { da } \\
\text { Prova }\end{array}$ & $\begin{array}{c}\text { A A licidade } \\
\text { de Aninha }\end{array}$ & $\begin{array}{c}\text { Chateação } \\
\text { de Aninha }\end{array}$ & $\begin{array}{c}\text { Aninha } \\
\text { ficou } \\
\text { Irritada }\end{array}$ & $\begin{array}{c}\text { A T ranqui- } \\
\text { lidade de } \\
\text { Aninha }\end{array}$ & $\begin{array}{c}\text { Um Dia } \\
\text { de } \\
\text { Tristeza }\end{array}$ & $\begin{array}{c}\text { A ninha } \\
\text { e seus } \\
\text { M edos }\end{array}$ \\
\hline $\begin{array}{c}\text { Categoria } \\
\text { Operacional }\end{array}$ & $\begin{array}{c}\text { Ansiedade/ } \\
\text { nervosismo }\end{array}$ & Felicidade & Chateação & $\begin{array}{c}\text { Irritação/ } \\
\text { raiva }\end{array}$ & $\begin{array}{c}\text { Tranqui- } \\
\text { lidade }\end{array}$ & Tristeza & M edo \\
\hline Instrumentos & $\begin{array}{c}\text { Desenho } \\
\text { da história }\end{array}$ & Argila & $\begin{array}{c}\text { Carinhas } \\
\text { emotivas }\end{array}$ & $\begin{array}{c}\text { Pintura } \\
\text { com tinta }\end{array}$ & $\begin{array}{c}\text { Carinhas } \\
\text { emotivas }\end{array}$ & $\begin{array}{c}\text { Desenho } \\
\text { espontâneo }\end{array}$ & $\begin{array}{c}\text { Jogo das } \\
\text { emoções }\end{array}$ \\
\hline
\end{tabular}

Q uadro 1 - Disposição dos encontros. Porto Alegre, RS, jun./ jul. 2009.

As carinhas (F igura 1), nome escol hido pelo grupo, for am introduzidas como for ma concreta de apoio à expressão das emoções, configurando as carinhas emotivas (CE) em um suporte visual às histórias ${ }^{(14)}$. Durante os encontros, emergiu a necessidade de se trabalhar a sétima emoção, "medo", história inicialmente não proposta pelo estudo.

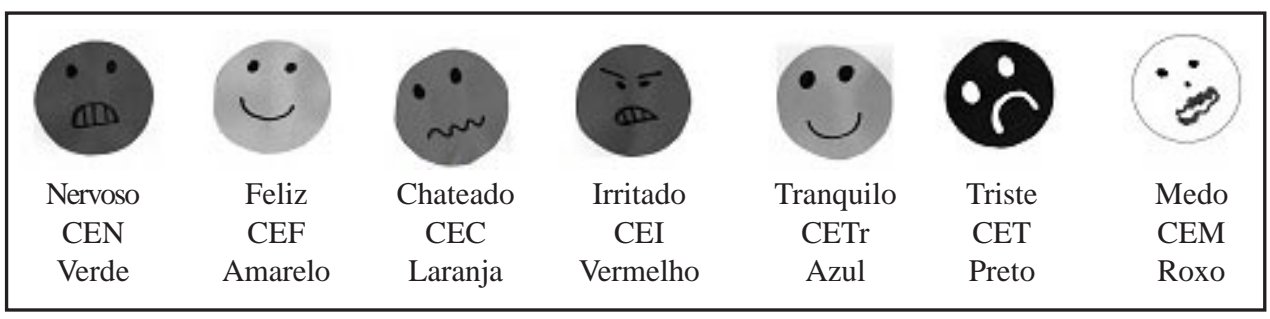

Figura 1 - As carinhas emotivas (CE ). Porto Alegre, RS, jun./ jul. 2009.

Entendendo ser um momento propício, para explorar a formulação da história pelas próprias crianças, criou-se o jogo das emoções. Este foi introduzido no último encontro. Cada jogador lançava o dado e, de acordo com o número lotado, andava com seu pino nas casas coloridas do tabuleiro do jogo. A o parar, sorteava-se uma carta com pergunta referente à cor - emoção: 0 que é? 0 que você faz quando está? 0 que faz parar a/ o? Diz uma situação que te deixa? 0 que/ quem te deixa? Você gostou da história, por quê? A cor roxa substituía essa última questão por "vamos construir a história do medo?".

Inicialmente, foram organizadas as categorias operacionais das sete emoções. As expressões verbais do grupo foram identificadas pelas iniciais dos nomes das crianças: P, F, Le, L, C, J; depois, as expressões não-verbais e percepções foram reunidas e apreendidas durante as narrativas, assim como, no diário de campo (DC), registrou-se o uso das carinhas e do jogo das emoções. A gruparamse, ainda, as fotografias das esculturas em argilas (A.P, A.J, A.C, A.F ), das pinturas (P.J e P.C) e dos desenhos digitalizados (D 1.L, D 1.Le, D 1.J, D 1.F, D 1.P, D 1.C, D 2.L , D 2.F, D 2.C e D 2.J).

Optou-se pela análise temática com triangulação dos dados. Essa se estrutura em etapas préestabelecidas de elaboração de instrumentos e verificação dos dados, prevendo, durante a constituição do universo estudado, sua validação pela exaustividade, representatividade, homogeneidade e pertinência ${ }^{(15)}$. A partir daí, originou-se o tema: o reconhecimento das emoções. 
Este trabal ho é parte do estudo monográfico apresentado ao Programa de Residência M ultiprofissional em Saúde ${ }^{(14)}$. Respeitou a Resolução 196/ 96 do Conselho N acional de Saúde ${ }^{(16)}$, diante da qual foi autorizada a participação dos pesquisados, através da assinatura do Termo de Consentimento Livre eE sclarecido pelos seus responsáveis. A pesquisa teve aprovação no Comitê de Ética, da Secretaria de Saúde do M unicípio de Porto Alegre, sob parecer $n^{\circ}$ 001.022764.09.7.

\section{RESULTADOS E DISCUSSÃO}

As histórias dispararam a ver balização dos sentimentos apresentados no grupo operativo, sendo esse um espaço para (re)significar as emoções infantis. 0 D ia da Prova, a primeira escol ha do grupo, trazia em seu enredo as dificuldades na escrita deA ninha, em um dia de prova. D urante a contação, as primeir as identificações com a per sonagem aparecem espontaneamente na passagem em que a nar rativa caracteriza o comportamento de A ninha roer as unhas, quando ansiosa:

\section{E u ruía [ unha] antes, só que agora eu cortei! (F ).}

Esse momento de externalização dos sentimentos advém do falar sobre a personagem, de voltar-se à história como um espelho, o qual proporciona desvelar, em falas, o que as crianças fazem quando estão nervosas.

Preocupado com alguma coisa [ ...] . É ! Q uando eu to nervoso $[$...] jogo tudo na parede (P).

É ter vontade dequebrar tudo! (F).

Verifica-se que, inicialmente, elas reconhecem a agressividade e a preocupação como nervosismo. No entanto, o não-reconhecimento dos momentos ansiosos também pode ser verificado na manifestação:

\section{E u não fico nervoso (L).}

0 participante do estudo, " $L$ ", mostrou-se ir ritadiço, calado, com dificul dade de inter ação com as demais crianças do grupo. A construção do desenho da história possibilitou constatar as identificações-projetivas, fenômeno no qual a criança identifica algo externo como seu próprio direito, como estar em união, um sentido inicial simbólico de $\operatorname{ser}^{(1)}$. No caso, verificáveis no desenho de " $F$ " (D 1.F ), a qual referiu desenhar a personagem roendo a unha enquanto ia para escola.

As ansiedades do grupo evidenciaram-se no desenho-cópia (D 1.L e), em que o garoto na recusa em desenhar, copiou a personagem da capa da história pela indisponibilidade de uso da régua por "L ". 0 desenho-cópia é um processo de elaboração importante, pois a intenção da criança não é a cópia do objeto e, sim, a construção do objeto a partir de sua interpretação/ el aboração ${ }^{(17)}$. Clarifica-se o fato de essas crianças demonstrarem a angústia de expor seus sentimentos e revelar-se diante do desconhecido. Todavia, nenhuma folha retornou em branco. U ma trazia "oi" em lápis preto (D 1.L), e outra um nome pequenino no canto superior da folha (D 1.J).

Examina-se a história O Dia da Prova como um "espaço potencial", visto que no encontro seguinte, ela foi solicitada para ser contada novamente, refletindo o trabalho simbólico do reconhecimento emocional da criança, já que consegue dar sentido aos seus sentimentos, representando sua identificação com a história(3-5).

A Felicidade de Aninha foi a segunda escoIha, possibilitando trabalhar as aflições e ansiedades infantis, ficando a felicidade, inicialmente, presente na contradição, na punição ou no castigo:

A gente não chora nem briga $(F)$.

A gente não fala mal dos outros quando a gente tá feliz (C).

As crianças foram capazes de reconhecer 0 "brincar" como indício de felicidade e identificá-lo capaz de desfazer sentimentos negativos como a tristeza, a raiva e o medo. A ssim, as crianças refer em o que fazem quando se sentem felizes:

Brincar! E u gosto de desenho [ assistir] (F).

G anhar no vídeo-game (P).

I gualmente, A Felicidade de Aninha despertou as noções infantis de felicidade, dando voz à criança, permitindo falar desse sentimento. A pós a contação seguiu-se à atividade com argila, que possibilitou a todos construir o que fazem quando estão felizes: bolinhos de chocolates (A.F ), campo de 
futebol (A.P), bonecas (A.C, A.F, A.J). "J", mais uma vez, teve dificuldades de expressar seus sentimentos e sua boneca não foi finalizada, ficando ora sem os membros, ora sem a cabeça.

0 brincar é um momento personificado, promotor da saúde mental infantil, permitindo que se evidenciem mecanismos de defesa como projeção e deslocamento. Por meio do brincar, a criança real iza manejo de suas fantasias e domínio de suas ansiedades, elaborando e reorganizando seu mundo interno ${ }^{(18)}$.

A comunicação infantil é complexa, de forma que as fantasias mais primitivas são inicialmente corporais, depois visuais e, mais tarde, verbais $s^{(17)}$. D essa for ma, o processo grupal, utilizando as narrativas e o brinquedo como suporte nos processos de elaboração das angústias infantis, possibilitou às crianças 0 encontro com a dor e seus significados.

No terceiro encontro, as crianças escolheram A Chateação de Aninha, emergindo a noção de chateação como contrariedade. A o discor darem da escolha da história, disputaram a escolha ao jogar "D iscordar", e um dos integrantes referiu ter ficado chateado e contrariado. D estaca-se a importância desse jogo na elaboração das dificuldades, sendo usado como uma forma de seguir em frente e trabalhar em conjunto.

$N$ esse encontro, foram introduzidas as "carinhas", e as crianças, ao se depararem com o material, tiveram a urgência de revelar os sentimentos mais profundos. Desse modo, elas foram pegando as imagens, uma a uma, e procurando nomeá-las.

E sse aqui tá chorando. E letá com cara de medo [ CET ] (L).

E sse aqui tá com cara de mau. E le vai bater no irmão [CEI] (F).

E mergiu uma discussão a respeito de várias emoções, com noções que ultrapassam o conhecer, indo ao encontro de (re)conhecer, entendido pela identificação da emoção como sua(1). As "carinhas" representaram uma guarida emocional às crianças que se empoderar am daquele objeto, enquanto narravam eventos conflitantes, externando emoções e desalojando as dores por meio de profundas revelações. Os mais tímidos e contidos puderam verbalizar seus limites em expressar as emoções:
E u choro por causa do meu pai quemorreu [ ...] Quando eu tô em casa eu me escondo [ ...] pra chorar (F).

A tá! A gora todo mundo vai ficar falando da vida!

[ É ruim falar das coisas da vida?]

E u não gosto!

[ $E$ tu fica triste às vezes?]

Às vezes

[ $\mathrm{E}$ tu chora?]

$\mathrm{N}$ ão! [ ...] só fico com aquela bola na garganta (L).

O clima ficou tenso, as crianças não queriam ouvir sobre dor, tornando-se evidente o quanto falar da tristeza incomodava-as. Relatos que referiam sintomas somáticos apareceram no grupo como uma forma possível de conviver com as angústias:

E u não queria ficar no colégio porque eu tava com dor de barriga [ ...] D e vez em quando, eu chego [ na escola mostrou CEF ] de vez em quando eu chego chorando [ mostrou CET ] (F).

0 início da vida escolar ameaça emocionalmente, pois é necessário responder às demandas sociais, para além de seus familiares, e desenvolver maiores capacidades cognitivas e emocionais. Quanto à somatização, destaca-se a conexão entre as primeiras fases do desenvolvimento, expressando a significação em atos. $\mathrm{Na}$ psicossomática psicanalítica, a organização pulsional embasa a constituição do sujeito; alude-se à pulsão situar-se na fronteira entre o mental e o somático, como um representante psíquico dos estímulos que se originam dentro do organismo e al cançam a mente ${ }^{(19)}$. T al fato confere à fala, a elabor ação de processos psíquicos internos, revelando novas saídas ao sofrimento, de (re)significar o falar através de histórias ${ }^{(4,5)}$.

As carinhas proporcionaram ao grupo de contação de histórias distanciamento, fazendo com que as crianças sentissem maior segurança, sendo um instrumento disparador da expressão verbal. A o final do encontro, o grupo avaliou, por meio da CE F, como positivo falar sobre seus sentimentos.

No quarto encontro, escolheu-se Aninha ficou Irritada. Esta discorre uma briga entre Aninha e sua amiga, necessitando do intermédio da professora e de um amigo para ser solucionada. A irritação provoca contrariedade nas crianças, aparecendo como nervosismo, um sentimento repreendido, refletido na desobediência e no castigo. 
Entretanto, o diferencial desse encontro está na proximidade do grupo, que possibilitou a verbalização do medo de " $C$ " de ter pesadelos. Assim, tiveram início relatos que perduraram até 0 momento da exposição da narrativa.

$\mathrm{N}$ a atividade de pintura, as crianças escolheram registrar a parte da história de que mais gostaram. P.J fez-se cópia fiel das cores que " $\mathrm{C}$ " utilizava para construir sua paisagem e a per sonagem da narrativa, porém "J" não conseguiu pintar nada além das flores. Já " $C$ " disse que não conseguia pintar A ninha irritada, somente feliz, conferindo a sua pintura a resolução do conflito.

Ao longo do processo grupal, no quinto dia, seus integrantes apresentavam maior cooperação, a conversa circulava espontaneamente e retomar 0 encontro anterior emergia deles próprios. Poder refletir sobre a irritabilidade foi necessário, e destaca-se que " $L$ " começou a manifestar suas ansiedades, até então, sufocadas:

E u finco no teclado em todas as teclas de raiva, dá uns piripaque (L).

$\mathrm{N}$ esse dia, foi escolhida $\mathbf{A}$ T ranquilidade de Aninha. Todavia, as crianças não estavam preparadas para fal ar sobre tranquilidade, pois, para elas, esse tema conferia-se justamente por poder falar a respeito de sua ausência. As conversas eram dispersas, as crianças agitaram-se a ponto de a narrativa ser iniciada duas vezes e inter rompida sem ser finalizada.

No sexto encontro, o grupo conseguiu falar de tranquilidade, de brincar, ficar calmo, ser feliz, formando a noção dos sentimentos bons. Pouco a pouco, relataram os acontecidos da semana e, logo, passaram para a nar rativa sobre a tristeza. A ninha tem seu animal de estimação atropelado, experienciando o luto.

Essa narrativa estimulou " $F$ " e " $C$ " a falarem sobre a morte. Havia chegado o momento de " $F$ ' falar sobre a morte do pai, que ocorreu repentinamente por fal ha na rede elétrica de casa. A pós sua fala, "C" quis falar sobre a morte de sua irmã menor de um ano. A ssim, expressar am-se as ações tristes:

Fica chorando (J).

F ica só na cama [ ...] trancada em vocêmesma [ ...] só no pensamento no seu cantinho $(F)$.
A pós a manifestação de reconhecimento das emoções, tanto pela fala como pela identificação com as carinhas, organizou-se o grupo para os desenhos espontâneos que se mostraram distinguidos do primeiro encontro. As crianças sorriam enquanto coloriam, "F" desenhou o grupo, incluindo a coor denadora e a observadora.

N o D 2.L, havia um sol sorridente, que ocupava toda a folha, completamente diferente do primeiro, que havia sido um "Oi" (D 1.L). Verificou-se um salto no $D 2$.J, uma paisagem em tons pastéis, difer entemente da fol ha assinada (D 1.J), da boneca incompleta (A.J) e da pintura-cópia (P.J). "J" produziu um desenho próprio e original, que revela a tranquilidade ofer ecida no grupo, onde a arte acabou tornando-se um apoio no qual a criança, ainda de maneira inconsciente, estrutura as emoções ${ }^{(5,13)}$.

0 encontro foi avaliado, utilizando as carinhas emotivas:

Antes eu tava assim [ mostrou CET ] [ ...] . A gora eu tô assim [ mostrou CEF] (F).

Os integrantes referiram que o grupo havia auxiliado a pensar sobre tranquilidade, refletido no insight que confer à contação de história sua contribuição ter apêutica na (re)significação e no reconhecimento das emoções infantis.

H oje éo dia da tranquilidade! Todo mundo tá precisando de tranquilidade! (F).

No último dia, o jogo foi introduzido, permeado pela elaboração da dor física e pelo reconhecimento das emoções do grupo expressado na seguinte fala:

E u [ ...] sempre tinha dor de barriga, depois que eu vim pra cá [ grupo] , a minha dor passou (F).

A cooperação do grupo emergia, e ouvir a dor do outro tor nava-se uma ponte para a própria elaboração, visível em " $\mathrm{L}$ " que incentivava as outras crianças com pal avras de conforto, auxiliava na leitura das perguntas sorteadas e possibilitou a fala:

Quando eu vou com minha mãe [ ...] eu choro [ ...] é porque, a vez que eu fui com o meu pai, minha vó tava doente [ ...] eu tenho medo que ela fique mal de novo [ ...] eu não vou nunca mais pra minha mãee pro meu pai (C). 
0 jogo mostrou-se capaz de validar as noções de felicidade, tristeza, nervosismo e medo trazidos anteriormente pelas crianças. 0 medo foi evidenciado e trabalhado no grupo, permeado de cooperação entre integrantes que, pouco a pouco, se organizaram para retomarmos ao jogo. Diante do sorteio da carta roxa, que indicava a criação de uma história do medo, o grupo elaborou:

A ninha é uma menina que tem medo de ficar sozinha em casa, no escuro, de dormir no quarto, de ficar de noite na rua, de barulhos, de fantasmas embaixo da cama. E la acorda de noitee sai correndo pro quarto da mãe, daí ela foi pro quarto mal-assombrado, elá, tinha explosivo. Aí, ela corre pro outro quar to e lá, ela ouve uma voz que pensa ser de um fantasma. E aí, ela dá um grito! A mãedela ouveevai correndo abraçá- la. E ficaram felizes para sempre Aí, ela acordou e era um sonho $(C, F, L, J)$.

No universo infantil, é necessário um lugar de onde se possa partir e voltar. Assim, na construção da história pel o grupo, cada um foi colocando suas frases, ou melhor, seus medos, (re)significando- $0 S^{(6)}$. Contar uma história é sempre um momento no qual se encenam os significantes antigos, aprisionados nos sintomas, e também suas transformações.

\section{CONSIDERAÇÕES FINAIS}

0 grupo de contação de histórias denota um espaço de promoção de saúde mental, capaz de proporcionar o enfrentamento e elaboração dos processos psíquicos infantis, presente na construção grupal pelas próprias crianças. 0 grupo reflete 0 empoder amento das crianças pela palavra, expondo e desmistificando os medos mais variados, desvelando noções do imaginário coletivo de felicidade eterna, ao mesmo tempo em que busca o enfrentamento real, 0 acordar de um sonho.

0 estudo oportunizou a expressão dos sentimentos, considerando que reconhecer as emoções e poder verbalizá-las propicia a diminuição de sintomas adoecedores, como a somatização, bem como a troca de condutas desadaptadas, por posturas e expressões mais saudáveis, mostrando-se como uma estratégia de promoção em saúde mental eficaz em vários dos seus aspectos.

Além disso, destaca-se que as histórias infantis, com temáticas específicas utilizadas, difer enciamse das clássicas por transpor a estrutura das nar- rativas ao cuidado à saúde, tornando-as estratégia de intervenção profissional que aborda a rotina infantil e concebe que a criança enfrenta dificuldades semelhantes às que os personagens vivenciam. T ais diferenças não impediram as histórias específicas sobre emoções de funcionarem como objeto transicional, capazes de reportar a outras emoções que não estavam inseridas naquele enredo, estimulando as crianças a verbalizarem seus sentimentos, o que confere a este instrumento importante propriedade.

Já o uso dos desenhos, pinturas e argilas facilitaram a comunicação em momentos tensos, bem como proporcionaram às crianças enfrentarem as emoções complexas desencadeadas, ora pela elaboração do próprio sentimento, ora pela verbalização do sofrimento por outro membro do grupo.

Por meio desta pesquisa, verificou-se o reconhecimento de quatro emoções básicas: alegria, tristeza, medo e nervosismo. A alegria foi localizada na vontade de brincar, no bem-estar do brinquedo e na ausência da agressividade, categorizando-se as reações emotivas de felicidade e tranquilidade. Já a tristeza verifica-se nas perdas, no luto, no silêncio e na dificuldade de percebê-la e verbalizá-la. 0 medo está na pior coisa do mundo, na morte e no ficar só. 0 nervosismo foi localizado nos comportamentos agressivos, identificado pelas crianças ora por nervoso, ora por irritação, ora como chateação, verificado na contrariedade e nas situações conflitantes.

A estratégia do grupo de contação de histórias pode ser uma ferramenta qualificada às ações de enfermagem na promoção de saúde mental infantil. A ponta-se, com isso, a necessidade de mais estudos com histórias específicas para que possam ser destacadas suas singularidades no campo da saúde.

\section{REFERÊ NCIAS}

1 W innicott DW. 0 brincar e a realidade. Rio de Janeiro: I mago; 1975.

2 Braga GC. Brincando e conhecendo a ciranda da vida: a for mação do círculo social da criança, portadora de transtorno mental, através da utilização de histórias infantis [ monografia]. Pel otas: F aculdade de E nfermagem e Obstetrícia, U niversidade Federal de Pelotas; 2007.

3 Bettelheim B. A psicanálise dos contos de fadas. $16^{a}$ ed. Rio do Janeiro: Paz e T erra; 2002. 
4 Gutfreind C. A utilização terapêutica do conto: uma pesquisa clínica. Rev Bras Psicoter. 2002;4(2):91-105.

5 Gutfreind C. Psicoterapia com crianças: benefícios do conto e da narratividade. Rev Bras Psicoter. 2004; 6(3):239-47.

6 Giongo AL. Histórias para brincar. Corr APPOA [ Internet] . 2005 [ citado 2009 ago 20];136:19-25. Disponível em: http:/ / www.appoa.com.br/ download/ correio136.pdf.

7 Castanha M L, L acerda M R, Zagonel IPS. Hospital: lugar para o enfermeiro cuidar do imaginário? Acta Paul Enferm. 2005;18(1):94-9.

8 Buss PM. Promoção da saúde e qualidade de vida. Ciênc Saúde Colet. 2000;5(1):163-77.

9 Buchele F, Coelho EBS, Linder SR. A promoção da saúde enquanto estratégia de prevenção ao uso das drogas. Ciênc Saúde Colet. 2009;14(1):267-73.

10 Ceribelli C, Nascimento LC, Pacifico SM R, Lima RA G. A mediação de leitura como recurso de comunicação com crianças hospitalizadas. R ev L atino-A m Enfermagem. 2009;17(1):81-7.

11 M aia EBS, Ribeiro CA, Borba RIH. Brinquedo terapêutico: benefícios vivenciados por enfermeiras na prática assistencial à criança e família. Rev $\mathrm{G}$ aúcha Enferm. 2008;29(1):39-46.
12 Pichon-Rivière E. 0 processo grupal. $7^{\text {a }}$ ed. Porto Alegre: M artins Fontes; 2005.

13 Pillar AD. Desenho e construção de conhecimento na criança. Porto A legre: Artes M édicas; 1996.

14 Braga G C. U m círculo de contação de histórias infantis: o re-conhecimento das emoções por crianças em um ambulatório de saúde mental infantil [ monografia] . Porto Alegre: Programa de Residência Multiprofissional em Saúde, Pontifícia Universidade Católica do R io G rande do Sul; 2009.

15 Bardin L. A nálise de conteúdo. 5ª ed. São Paulo: E dições 70 Brasil; 2009.

16 M inistério da Saúde (BR), Conselho Nacional de Saúde. Resolução 196, de 10 de outubro de 1996: diretrizes e normas regulamentadoras de pesquisa envolvendo seres humanos. Brasília (D F); 1996.

$17 \mathrm{~N}$ eto A. 0 que dizem os desenhos infantis? Pediatr M od. 1997;32(4):88.

18 Castro M GK. Reflexões acerca da prática da psicoterapia com crianças: uma ponte entre passado, presente e futuro. Rev Bras Psicoter. 2004;6(3):30116.

19 M ello F ilho J. Concepção psicossomática visão atual: contribuições da psicanálise. $9^{a}$ ed. São Paulo: Casa do Psicólogo; 2002.

\author{
E ndereço da autora / D irección del autor / \\ A uthor's address: \\ G imene Cardozo Braga \\ Rua G eneral Telles, 223, Centro \\ 96010-310, Pelotas, RS \\ E-mail: gcardozobraga@yahoo.com.br
}

Recebido em: 28/ 10/2010

A provado em: 19/02/2011 